\title{
Pelvic Reconstruction after Chronic Pubic Symphysis Diastasis and Bladder Herniation
}

\author{
Carlos Roberto Schwartsmann ${ }^{1,2 *}$, Renan Castanho de Campos Leite', \\ Henrique Marquardt Lammerhirt ${ }^{2}$, Leandro de Freitas Spinelli ${ }^{3,4}$, Ary da Silva Ungaretti Neto ${ }^{2}$
}

${ }^{1}$ Federal University of Health Sciences of Porto Alegre/RS, Porto Alegre, Brazil

${ }^{2}$ Orthopedics and Traumatology Service of the Santa Casa de Porto Alegre Hospitalar Complex, Porto Alegre, Brazil

${ }^{3}$ Department of Surgery, Federal University of Health Sciences of Porto Alegre/RS, Porto Alegre, Brazil

${ }^{4}$ Laboratory of Bioengineering, Biomechanics and Biomaterials, Department of Mechanical Engineering, University of Passo

Fundo, Passo Fundo, Brazil

Email: *schwartsmann@gmail.com

How to cite this paper: Schwartsmann, C.R., de Campos Leite, R.C., Lammerhirt, H.M., de Freitas Spinelli, L. and da Silva Ungaretti Neto, A. (2020) Pelvic Reconstruction after Chronic Pubic Symphysis Diastasis and Bladder Herniation. Open Journal of Orthopedics, 10, 161-165. https://doi.org/10.4236/ojo.2020.108018

Received: April 24, 2020

Accepted: August 1, 2020

Published: August 4, 2020

Copyright ( 2020 by author(s) and Scientific Research Publishing Inc. This work is licensed under the Creative Commons Attribution International License (CC BY 4.0).

http://creativecommons.org/licenses/by/4.0/

\begin{abstract}
The research proposes a surgical technique for patients with chronic pubic symphysis diastasis and bladder herniation by means of a pelvic reconstruction technique. Three patients were treated initially in other hospitals and referred to us. All presented with pubic symphysis diastasis greater than $7 \mathrm{~cm}$ and bladder herniation. Two patients were initially treated with external fixation, and in one patient, the symphysis diastasis had been completely neglected. All cases presented good evolution with the proposed technique, which is described in details in the paper.
\end{abstract}

\section{Keywords}

Pelvic Reconstruction, Pelvic Disruption, Pelvic Diastasis

\section{Introduction}

Pelvic fracture with pubic diastasis is a result of high-energy anteroposterior compression injury (APC). There is a general consensus on the need for adequate surgical fixation and stabilization when the symphyseal gap exceeds $2.5 \mathrm{~cm}$. External fixation could promote early stabilization and is sometimes the only treatment required [1]. However, when the pubic diastasis is not treated accordingly, it could evolve into bladder herniation [2]. This is an unusual sequel, and few surgical techniques to address it are described in the literature. The purpose of this paper is to introduce a new technique for the treatment of largely neglected symphysis diastasis with bladder herniation. 


\section{Patients}

Our three patients were treated initially in other hospitals and referred to us. There were one male and two female patients, ageing 70, 64 and 52 years-old respectively, without any comorbidities. All presented with pubic symphysis diastasis greater than $7 \mathrm{~cm}$ and bladder herniation. Two patients were initially treated with external fixation, and in one patient the symphysis diastasis had been completely neglected. In all cases, the trauma had occurred more than 18 months earlier. Radiologically, all patients had an open book injury, the result of an anteroposterior compression, classified by Young and Burgess as APC III. Ethical clearance was obtained from the Ethical Committee of our institution.

\section{Surgical Technique}

The pubic symphysis is exposed through a Phannenstiel incision. The incision is centred on the midline approximately $1.5 \mathrm{~cm}$ above the pubis. The subcutaneous tissues and superficial fascia are divided in line with the skin incision, exposing the rectus abdominus fascia. The rectus fascia is divided longitudinally in the midline along the intermuscular raphe. The rectus attachment to the pubis is disrupted, then the superior and posterior surface of the pubis are exposed subperiosteally. Care must be taken to protect the bladder. The diastasis gap is measured (Figure 1(a)) A second incision is made on the iliac crest just posterior to the anterior superior iliac spine. The iliac crest is dissected, and then a tricortical bone $1 \mathrm{~cm}$ longer than the gap measured is removed (Figure 1(b)). The pubic rami are cruentated without trying to reduce the gap, then the iliac crest graft is fit under pressure as a bone bridge (Figure 1(c)) and fixed with a $3.5 \mathrm{~mm}$ DCP plate and screws (Figure 1(d)).

\section{Tips and Tricks}

We recommend to measure the gap prior to the resection of the graft from the iliac crest. It is also possible to obtain a 3D printing model in order to premold the plate and to study the surgical procedure with the medical team.

\section{Discussion}

The research presents a case series of patients with pelvic reconstruction after chronic pubic symphysis diastasis and bladder herniation, and proposes a surgical technique.

Pelvic ring fractures are high-energy traumas, associated with high morbidity and mortality. In some cases, a damage control surgery with an external fixation is the best option. However, biomechanical studies have shown that an external frame cannot ensure sufficient stability to allow mobilization without the risk of redisplacement of the fragments, particularly those with vertical instability. This probably happened with our first two cases; both had used external fixation as treatment. The third case had been completely neglected. All cases presented good evolution with the proposed technique (Figures 2-4). 


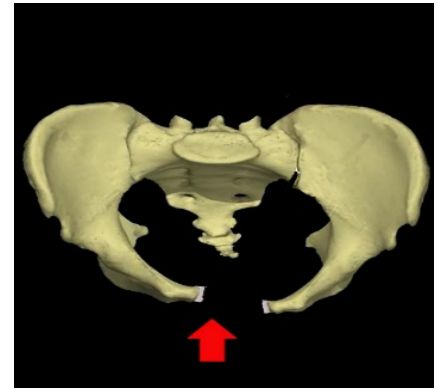

(a)

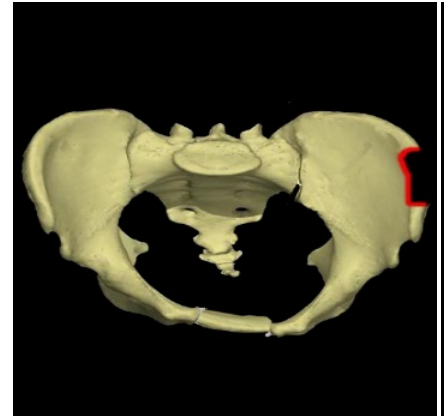

(c)

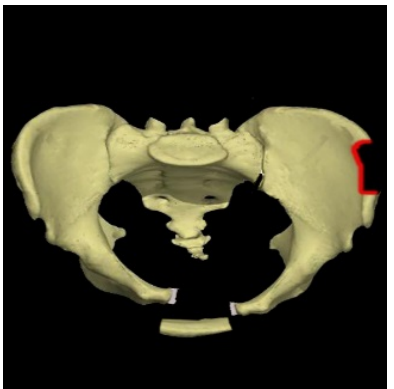

(b)

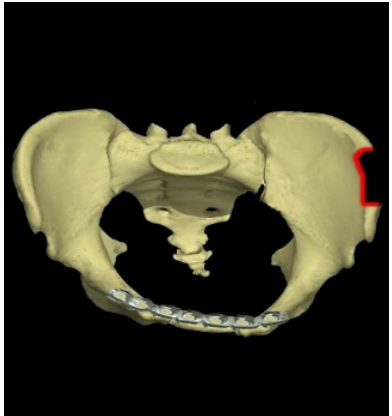

(d)

Figure 1. Demonstration of the surgical technique: (a) Schematic draw showing the pubic diastasis (red arrow); (b) Tricortical bone graft was taken from the iliac crest and transferred to the diastasis; (c) After scaring both the pubic bone ends, the iliac crest graft is inserted between the gap; (d) The graft is fixed with plate and screws.

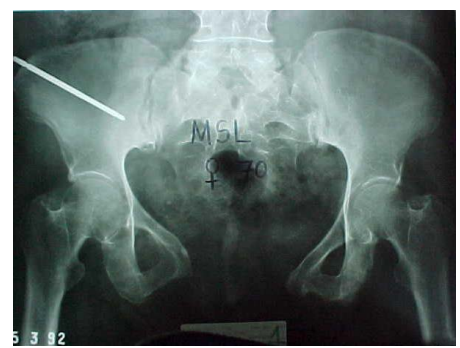

(a)

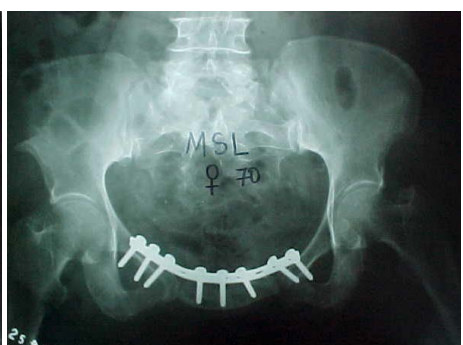

(b)

Figure 2. Radiologic Images. (a) Preoperative X-ray before reconstruction. Diastasis of $8.2 \mathrm{~cm}$; (b) Postoperative X-ray showing the reconstruction.

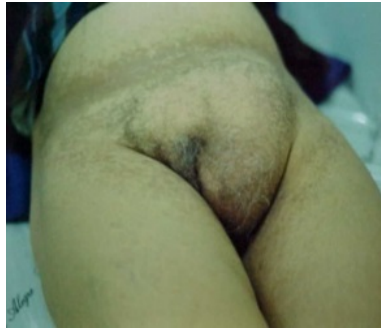

(a)

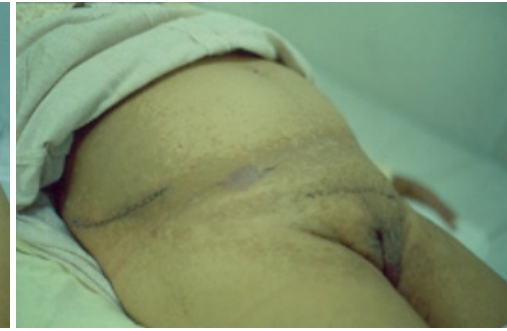

(b)

Figure 3. Clinical Images. (a) Before surgery; (b) Immediately clinical result.

Few case reports in the literature describe solutions to these problems. Foster et al. described a similar case with a pubic disruption of $7 \mathrm{~cm}$ and bladder herniation 


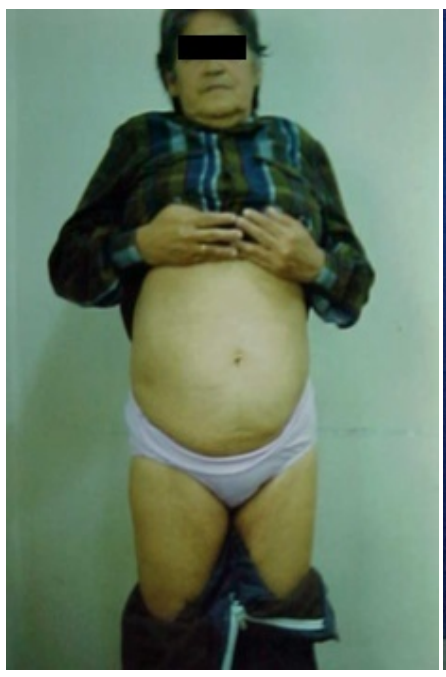

(a)

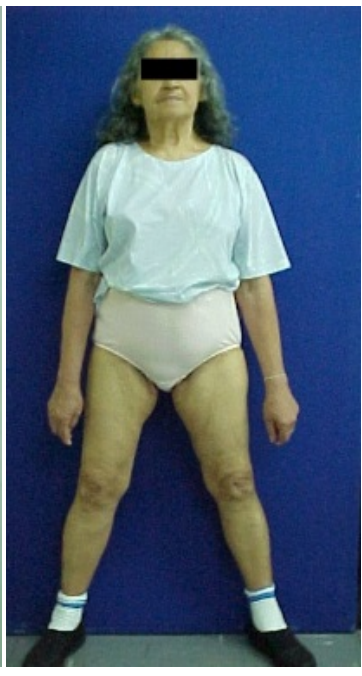

(b)

Figure 4. Long-term clinical result. (a) 2 years follow-up; (b) 13 years follow-up.

[3]. They repaired the defect with an autogenous tibial cortical bone graft. Grolleau et al. reported a case with diastasis of $5 \mathrm{~cm}$ treated with a prosthesis and an abdominal muscular flap [4]. Seckiner et al. opted to use an allograft of tibial cortical bone fixed with a $3.5 \mathrm{~mm}$ DCP plate and screws [5]. This option is similar to ours but depends on a tissue bank, which is not always available. Tabib et al. described a case with $4 \mathrm{~cm}$ of pubic diastasis, in which they grafted an iliac crest tricortical bone and performed fixation with a cerclage [6].

\section{Conclusion}

Acute reduction of the pubic symphysis disruption is always the best option, but when there is an unsatisfactory reduction with a gap greater then $2.5 \mathrm{~cm}$, the possibility of pelvic organ herniation must be considered. Chronic diastasis with bladder herniation is a rare condition, few cases of which are reported in the literature. Reconstruction of the pubic symphysis diastasis with an iliac crest tricortical autograft bone is a simple, effective and low cost biological solution.

\section{Conflicts of Interest}

The authors declare no conflicts of interest regarding the publication of this paper.

\section{References}

[1] Burgess, A.R., Eastridge, B.J., Young, J.W., Elliston, T.S., Elliston Jr., P.S., Poka, A., Bathon, G.H. and Brumback, R.J. (1990) Pelvic Ring Disruptions: Effective Classification System and Treatment Protocols. Journal of Trauma, 30, 848-856. https://doi.org/10.1097/00005373-199007000-00015

[2] Fuhs, S.E., Herndon, J.H. and Gould, F.R. (1978) Herniation of the Bladder. JBJS, 60, 704-707. https://doi.org/10.2106/00004623-197860050-00022

[3] Foster, E.J., Murray, D.G. and Gregg, R.O. (1981) Chronic Bladder Herniation As- 
sociated with Pubic Diastasis. Journal of Trauma, 21, 80-81.

https://doi.org/10.1097/00005373-198101000-00019

[4] Grolleau, J.L., Vazzoler, N. and Chavoin, J.P. (1999) Transpubic Herniation of the Bladder: A Sequel of Traumatic Pubic Symphysis Diastasis. Hernia, 3, 85-88.

https://doi.org/10.1007/BF01194612

[5] Seckiner, I., Keser, S., Bayar, Y. and Mungan, A. (2007) Successful Repair of a Bladder Herniation after Old Traumatic Pubic Symphysis Diastasis Using Bone Graft and Hernia Mesh. Archives of Orthopaedic and Trauma Surgery, 127, 655-657. https://doi.org/10.1007/s00402-007-0290-2

[6] Tabib, W., Mitilian, D., Pauthier, F. and Ghiles, E. (2010) Herniation of the Bladder after Recurrent Pubic Symphysis Diastasis. European Journal of Orthopaedic Surgery \& Traumatology, 20, 497-500. https://doi.org/10.1007/s00590-010-0595-7 